\section{Powieść aplikacja - między wolnym czytaniem a szybkim Internetem}

Bartosz Lutostański, Magdalena Rembowska-Płuciennik

TEKSTY DRUGIE 2020, NR 5, S. 53-72

DOI: 10.18318/td.2020.5.5 | Bartosz Lutostański ORCID: 0000-0001-6345-3275

Magdalena Rembowska-Płuciennik ORCID: 0000-0002-8800-3550

Panu Profesorowi Zdzisławowi Łapińskiemu, nieustraszonemu czytelnikowi nowości

$\mathbf{H}$ istorię literatury cyfrowej dzieli się zazwyczaj na cztery fazy'. Jednak ostatnio obserwujemy nowy trend: wykorzystanie aplikacji na urządzenia mobilne (np. smartfon lub tablet) jako nośnika dla tekstów

1 Hipertekst stanowi najważniejszy przykład pierwszej fazy literatury cyfrowej (zob. A. Bell The Possible worlds of hypertext fiction, Palgrave Macmillan, Houndmills 2010, s. 1-2; R. Page, B. Thomas Introduction, w: New narratives: stories and storytelling in digital age, ed. by R. Page, B. Thomas, University of Nebraska Press, Lincoln-London 2011, s. 1-3); druga faza charakteryzuje się wykorzystaniem bogatego zaplecza zasobów multimodalnych i multimedialnych (A. Bell, A. Ensslin, H.K. Rustad From theorizing to analyzing digital fiction, w: Analyzing digital fiction, ed. by A. Bell, A. Ensslin, H.K. Rustad, Routledge, New York-London 2014, s. 9; N.K. Hayles Electronic literature. New horizons for the literary, University of Notre Dame, Notre Dame 2008); trzecią określa się za Espenem Aarsethem "cybertekstową" (Cybertekst. Spojrzenia na literaturę ergodycznq, przeł. D. Sikora i in., Korporacja ha!art, Kraków 2014); natomiast ostatnią, czwartą, Hans Kristian Rustad opisuje jako "social media literature" (A. Bell, A. Ensslin, H.K. Rustad From theorizing to analyzing..., s. 10).
Bartosz Lutostański - dr, adiunkt w Instytucie Anglistyki UW; autor monografii Gombrowicz-Beckett. Beckett-Gombrowicz. A Comparative Inter-modal Study (2016); redaktor gościnny numerów czasopisma "Tekstualia" poświęconego intermedialności (2018, nr 1) i transmedialności (2019, nr 3); założyciel i kierownik grupy badawczej ORGiN (UWM, 2018-2019). W najnowszym projekcie naukowym pracuje nad formami narracji w nowych mediach cyfrowych. Kontakt: b.lutostanski@ uw.edu.pl

Magdalena Rembowska-Płuciennik - dr hab. prof. IBL PAN, kierownik Pracowni Poetyki Historycznej, teoretyczka i historyczka literatury. Zainteresowania badawcze: narratologia kognitywistyczna, empiryczne badania nad odbiorem literatury, antropologia literacka. Publikowała w "Tekstach Drugich", „Pamiętniku Literackim”, "Zagadnieniach Rodzajów Literackich, "Language and Literature." Kontakt: magdalena.rembowska-pluciennik@ibl.waw.pl 
literackich. Niekiedy ten format określa się mianem literatury „na małym ekranie"2 lub „opartej na aplikacji”." Należą do niego np. The Pickle Index Eli Horowitza (2015), Arcadia Iaina Pearsa (2018) i Belgravia Juliana Fellowesa (2020).W niniejszym artykule skupimy się tylko na pierwszym i pionierskim utworze, bardzo dobrze ocenianym przez recenzentów, ,jedynym w swoim rodzaju"4 . The Pickle Index to w istocie multimedialna seria powieściowa, składająca się z dwóch książek drukowanych i aplikacji. Każda z edycji powieści prezentuje różne typy czytelniczego odbioru, charakterystyczne dla powieści drukowanej, powieści wizualnej, dzieła liberackiego ${ }^{5}$, powieści cyfrowej i aplikacji właśnie. Różnice w odbiorze wymienionych modeli ujawniają się w trakcie lektury całej serii, ale również są stematyzowane w treści utworu - zostają wprowadzone na poziom metamedialny. W niniejszym artykule opiszemy nie tylko poetykę The Pickle Index jako „powieści na małym ekranie”, ale również porównamy specyfikę medialną każdej z wydanych wersji utworu Horowitza. Wskażemy miejsca napięć rodzących się na styku mediów oraz możliwości doświadczeniowe, jakie oferuje każde z nich swemu czytelnikowi $i^{6}$ To właśnie możliwość zderzenia ze sobą różnych potrzeb, praktyk czytania i przyzwyczajeń komunikacyjnych odbiorcy w dobie wielomedialnego czytelnictwa wydaje się najważniejszym tematem The Pickle Index, choć nie był on podnoszony przez krytyków tej powieści aplikacji.

\section{The Pickle Index: instrukcja konsumpcji}

W The Pickle Index odnajdziemy nawiązania do tradycyjnych gatunków literackich (satyra, antyutopia, dziennik), a także do form dziennikarskich

2 A. Ensslin, L. Swanstrom, P. Frelik Introducing small screen fiction, w: Small screen fiction, numer specjalny czasopisma "Paradoxa” 2017 No. 29, s. 7-17. Serge Bouchardon zapropował jeszcze jeden termin, "touchscreen fiction” Figues of gestural manipulation, w: A. Bell, A. Ensslin, H.K. Rustad Analyzing digital fiction..., S. 159-175.

3 A. Alter A novelist's page-turner will take swipes instead, "New York Times” 4 grudnia 2015. https://search.proquest.com/docview/1739282563?accountid=14887 (10.02.2020). Ch. Locke The Pickle Index, www.wired.com/2015/11/the-pickle-index/ (15. 08.2020).

5 A. Przybyszewska Liberackość dzieła literackiego, Wydawnictwo UŁ, Łódź 2015; K. Bazarnik Liberature: A Book-bound genre, Wydawnictwo UJ, Kraków 2016.

6 A. De Fina, S. Perrino Introduction, w: Storytelling in the digital world, ed. by A. De Fina, S. Perrino, John Benjamins Publishing, Amsterdam 2019, s. 3. Por. cele komparatystyki intermedialnej wskazane przez A. Hejmeja Intermedialność $i$ komparatystyka intermedialna , „Przegląd Humanistyczny" $2013 \mathrm{nr}$ 4, s. 13-18. 
(wiadomość, reportaż) czy odmian komunikacyjnych zaczerpniętych z mediów społecznościowych (np. blog i posty). Powieść Horowitza została wydana w trzech odmiennych wersjach: pierwsza w miękkiej okładce; druga, w twardej, składająca się z dwóch oddzielnych części , oraz trzecia jako aplikacja na urządzenia mobilne ${ }^{8}$. Zasadnicza różnica między obiema edycjami drukowanymi sprowadza się do wyboru strategii przedstawienia dwóch głównych i rozbieżnych punktów widzenia na wydarzenia opowiedziane w powieści.

Pierwszy punkt widzenia prezentuje The Daily Scrutinizer, propagandowa gazeta codzienna wydawana przez rząd. Jej redaktorem i autorem dostępnych nam artykułów jest Hank Hamper, który opisuje wydarzenia z dziesięciu kolejnych dni, przede wszystkim zaś aresztowanie i proces sądowy Zlotego Kornblatta, kierownika cyrku i rzekomego zdrajcy narodu. Przyświeca mu jeden cel - szerzenie propagandy autorytarnego państwa, propagowanie wśród obywateli zachowań wymaganych przez dyktaturę oraz wskazywanie wrogów stanu i ich ostra krytyka. Wszystko to przy wykorzystaniu niezwykle patetycznego i kwiecistego języka.

Drugi punkt widzenia w powieści należy do Flory Bialy, asystentki Zlotego, która codziennie sporządza relacje zdarzeń z mijającego dnia i zamieszcza je nielegalnie w sieci, na państwowej platformie społecznościowej o nazwie The Pickle Index. Czyni to jednak z pobudek osobistych, a nie politycznych. Co więcej, Flora przedstawia inne postaci z cyrku, opisuje je oraz własną przeszłość, omawia życie codzienne w Destinie. Z tego względu jej zapiski gatunkowo przynależą zarówno do form autobiograficznych, dziennikowych lub epistolarnych znanych z pierwszych powieści oraz współczesnych postów w mediach społecznościowych.

7 Za część wizualną tej wersji powieści Horowitza odpowiadał lan Huebert.

8 Jej współautorem jest programista i producent, Russell Quinn.

9 Akcja rozgrywa się w autorytarnym państwie o nazwie Destina. Szczególne miejsce w kulturze jego mieszkańców zajmują... tytułowe pikle, z dumą kultywowane dziedzictwo kulinarne i istota narodowej tożsamości promowana przez dyktaturę. Powieść opowiada historię trupy cyrkowej poszukującej swojego szefa i przywódcy, Zlotego Kornblatta, który niespodziewanie zostaje zatrzymany przez policję i przewieziony do najcięższego więzienia Destiny. Jego zespół postanawia go znaleźć i uwolnić. Jedna z członkiń trupy, Flora Bialy, zamieszcza szereg tajnych wpisów na oficjalnej medialnej platformie państwowej Pickle Index, opisując dzieje cyrku i przebieg poszukiwań. Zloty otrzymuje wyrok śmierci, ale on i jego grupa zostają uratowani, gdy tłum zgromadzony na miejscu kaźni rozpoznaje ich na podstawie tajnego pamiętnika Flory. W iście rabelaisowskim stylu egzekucja zmienia się w spektakl przypominający programy spod znaku "Mam talent", a rozwój wydarzeń prowadzi do obalenia autorytarnego rządu. 
Obie te perspektywy można poznać w różnych konstelacjach w zależności od wyboru którejś z dwóch symultanicznie istniejących edycji. To czytelnik decyduje, w jakim układzie będzie poznawać losy bohaterów, podobnie jak rozmaicie można czytać Grę w klasy Julio Cortázara. Relacje Hanka Hampera i Flory Bialy zostały umieszczone naprzemiennie w wersji jednoczęściowej The Pickle Index. Natomiast w wydaniu dwuczęściowym - są zupełnie rozdzielone: część z The Daily Scrutinizer zawarto w tomie z szarą okładką i zatytułowano "Wiadomości, natomiast relacje Flory znajdują się w części Przekąski (okładka koloru czerwonego). Edycję dwuczęściową powieści wydano w kartonowym pudełku, które fizycznie spaja je w całość. W ten sposób alternatywne wersje wydarzeń zderzono ze sobą jeszcze bardziej; istnieje szansa, że czytelnik decydujący się na zapoznanie z tylko jednym tomem nigdy nie pozna lustrzanego odbicia wydarzeń zawartego w pominiętej książce. Gdy natomiast decyduje się przeczytać jedną po drugiej, decyzja o wyborze kolejności rzutuje nieuchronnie na obraz świata i motywacje bohaterów; cały czas musi orientować się wobec oficjalnej i nieoficjalnej wersji historii, konfrontować się z przemocą agitacji lub z kuszącą subwersywną opowieścią Flory. Na pierwszych stronach znajdziemy swoistą instrukcję obsługi tej niecodziennej formy: „The Pickle Index jest skonturowany tak, by rozdziały czytane były na przemian - najpierw jeden rozdział z tej części [Wiadomości], a następnie rozdział z drugiej [Przekąski], przez każdy dzień trwania historii"10. W każdej części mamy dziesięć rozdziałów, a zatem czytelnicy mogą przeczytać dialogiczną treść powieści w ciągu półtora tygodnia. Te sugestie dotyczące trybu lekturowego czytelnik może oczywiście zlekceważyć, stanowią one jednak propozycję ekwiwalentyzowania tego doświadczenia, które przynosi jedynie aplikacyjna wersja powieści: narzuconego systemowo porcjowania lektury. Trudno nie zobaczyć w tym geście żartobliwego nawiązania do odcinkowości drukowanych w prasie XIX-wiecznych powieści. Stworzeniu ramy dziennej jako modusu lektury książki drukowanej służy także przemyślany wybór gatunków, jakie wykorzystano konstrukcyjnie w tej wielomedialnej serii. Dzień lekturowy naśladuje bowiem relacja dziennikarska z bieżącego dnia czytelnika prasy oraz relacja dziennikowa z autobiograficznych wpisów Flory.

Warto podkreślić dodatkowy element konstrukcyjny dwuczęściowego wydania The Pickle Index, o niebagatelnym znaczeniu dla specyfiki odbioru tej wersji historii pechowych cyrkowców. Czytelnicy nie tylko zostają

10 "The Pickle Index is designed to be read in alternating chapters, first this book and then the other one, for each day of the story" (przeł. B.L. i M.R.-P.). 
poinstruowani o tym, by czytać jeden rozdział z każdej części każdego dnia, co de facto wymusza na nich fizyczne operowanie książkami w trakcie lektury. Dodatkowo mają oni układać ilustracje, które poprzedzają każdy rozdział, w celu dopasowania ich w jeden, duży obraz, o czym również czytamy na pierwszych stronach obu części (rys. 1). W rezultacie ta konkretna edycja

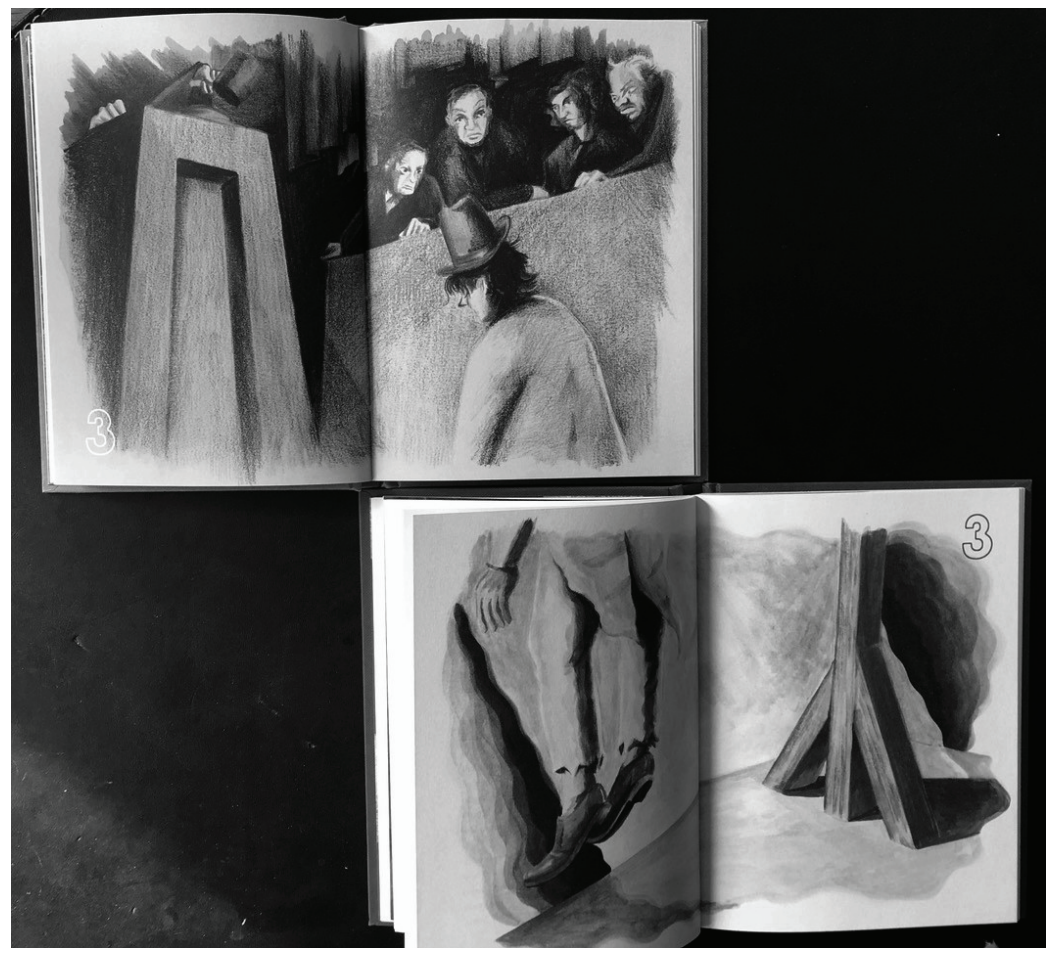

powieści Horowitza wymusza wyraźniejszy wymiar fizyczny lektury (haptyczny ${ }^{11}$ ) oprócz typowego gestu przekładania stron. Biorąc zatem pod uwagę złożoność semiotyczną utworu nawet w jego wersji drukowanej, należałoby

11 Na temat różnicy w znaczeniu pomiędzy haptycznością a taktylnością, zob. np. D. Marques Through the touching glass. literature for haptic inter[(surf)aces], „Poétiques et esthétiques numériques tactiles: Littérature et arts", Laboratoire NT2, no 8, http://nt2.uqam.ca/en/cahiers-virtuals/ article/through-touching-glass-literature-haptic-intersurfaces (8.08.2020). Zob. także A. Przybyszewska O retoryce rozgrywania i dotyku oraz niektórych strategiach otwarcia na czytelnika w wybranych przykładach literatury nowomedialnej, „Teksty Drugie” 2016 nr 1, s. 169-188. 
go określić jako multimodalny ze względu na obecność dodatkowych kodów - wizualności rysunków i haptyczności procesu lektury ${ }^{12}$. Natomiast sami czytelnicy muszą przeczytać powieść oraz w pewnym stopniu ją (od) tworzyć. The Pickle Index to zatem nie tylko starannie wykonana hybryda kodów semiotycznych, ale również produkt, kwestionujący (lub sprawdzający) granice materialności narracji zrealizowanej poprzez różne media i w ramach odmiennych technologii. Cechy obecne w jednym medium (narracja cyfrowa czy wizualna) znajdują w tym skomplikowanym układzie swe bliższe lub dalsze odpowiedniki w innym medium (narracja w książce drukowanej). Operowanie stronami w celu odnalezienia właściwej kombinacji rysunków można porównać do mechaniki łączenia treści w kolejnych linkach (leksjach) hipertekstu. Operowanie książką jako przedmiotem materialnym wprowadzają kinetykę w proces percepcji tekstu drukowanego, odsyłając do tego typu materialności, jaki systemowo gwarantuje technologia służąca opowiadaniu na małym ekranie: za pomocą własności aplikacji mobilnej.

Nastawienie porównawcze względem różnych mediów czytelniczych zostaje zatem celowo wpisane w koncepcję lektury całości na poziomie metamedialnym. Eli Horowitz rzuca czytelnikom serii (a więc także aplikacji) wyzwanie, by odnaleźli się w środowiskach diametralnie różnych i porównali je na swój użytek. Dzisiejszy mól książkowy może wybrać, który typ najbardziej mu odpowiada. Jak czytamy we Wskazówkach (które stanowią hipotetyczną rozmowę czytelników z twórcami aplikacji, utrzymanych w poetyce formularza „najczęściej zadawanych pytań”), każdy typ lektury jest dozwolony: „Wydaje nam się, że możesz preferować papierową wersję opowieści w twardej okładce [dwuczęściowa], albo nawet tę w miękkiej okładce [jednoczęściowa] lub na Kindle’u, by uniknąć wszelkich dziwactw” oraz „Celem całego przedsięwzięcia jest wykorzystanie atutów i ograniczeń każdego formatu, zamiast symulowania jednego i tego samego doświadczenia lektury we wszystkich mediach"13.

Należy zwrócić uwagę, że teoria powieści multimodalnej (np. A. Gibbons Multimodality, cognition, and experimental literature, Routledge, New York-London 2011; W. Hallet The rise of the multimodal novel. Generic change and its narratological implications, w: Storyworlds across media, ed. by M.-L. Ryan, J.-N. Thon, University of Nebraska Press, Lincoln-London 2014, s. 151-172) zazwyczaj pomija wymiar haptyczny powieści.

"Sounds like you might prefer the hardcore edition - or even the paperback or Kindle, for even fewer wangdoodles" oraz "The goal is to take advantage of the specific advantages and limitations of each format, rather than attempting to simulate an identical experience across all media". 


\section{Aplikacja The Pickle Index}

Trzecia wersja powieści Horowitza ma formę aplikacji, którą można zainstalować na własnym urządzeniu mobilnym. Interfejs aplikacji składa się z trzech centralnych elementów: „Indeksu”, „Dziś” i „Przepisów”; dodatkowo zawiera on mapę kraju oraz sekcję Q\&A (rys. 2). Pierwszy z elementów

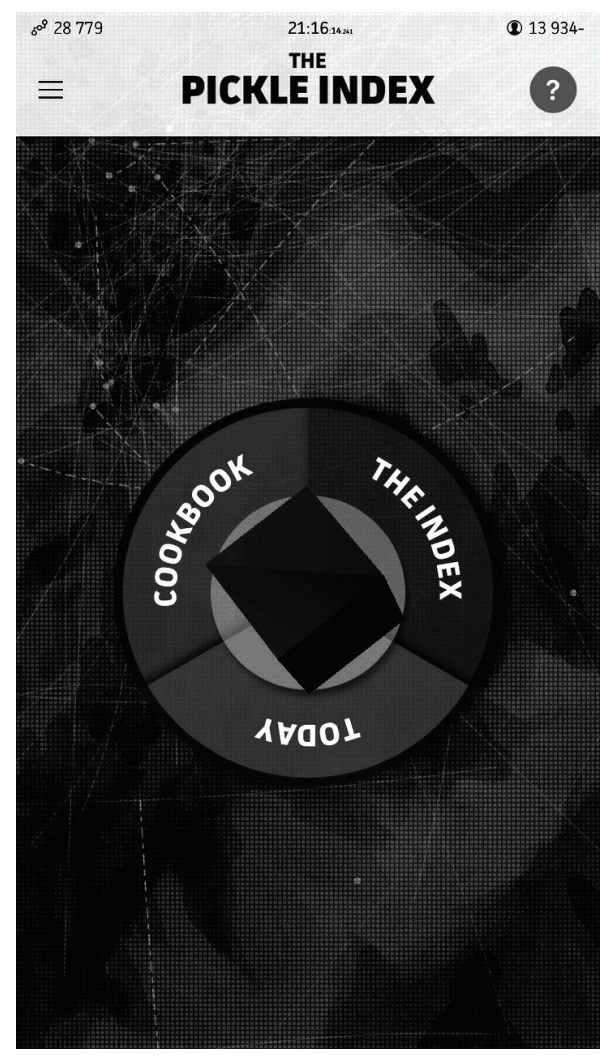

to oficjalne kompendium przepisów na kiszonki, drugi - kanał informacyjny, w którym można znaleźć te same treści co w „Wiadomościach” z wersji papierowej, a z kolei trzeci stanowi zbiór przepisów zamieszczonych przez innych użytkowników aplikacji. Aplikacja nie stanowi zatem prostego „przepisania" powieści tradycyjnej na kod cyfrowy, jest bowiem istotnym rozwinięciem świata powieści, łączącym multimedialne komponenty z mechanizmami interaktywności. Co więcej, aplikacja robi coś, czego powieść nie

\section{http://rcin.org.pl}


może - aktywnie kontroluje proces lektury, przyznając nam dostęp jedynie do dwóch rozdziałów na dzień (jeden z The Daily Scrutinizer i drugi autorstwa Flory). Czytanie nosi zatem cechy serialności ${ }^{14}$. Istotne w procesie odbioru utworu stają się wymuszone przerwy w dostępie do kolejnych jego części. W kontekście The Pickle Index są one ważne z trzech zasadniczych powodów. Po pierwsze, aplikacja ustanawia dokładną ramę czasową rozwoju fabuły, jako że każdy kolejny rozdział traktuje o wydarzeniach z poprzedniego dnia. Dzięki temu realistycznemu zabiegowi dowiadujemy się, co wydarzyło się u głównych bohaterów, w sposób ściśle chronologiczny, dzień po dniu, $\mathrm{z}$ dwóch różnych perspektyw (Hanka i Flory). W dodatku, zgodnie z podtytułem (POWIEŚĆ W 10 DNIACH albo ...W1o DNI), utwór Horowitza ujawnia od razu granicę rozwoju akcji rozpisanej na dwadzieścia rozdziałów (odcinków). Czytelnicy od początku zatem są świadomi tego, że opowieść w ich dłoniach rozegra się w tym czasie, co jednoznacznie organizuje doświadczenie lektury i orientuje je na nieodległą przyszłość (spodziewamy się rozwiązania najważniejszych problemów w odpowiednim momencie fabuły). Last but not least, w oczekiwaniu na kolejny rozdział czytelnicy mogą (a nawet muszą) wejść w interakcję ze środowiskiem aplikacji, np. poprzez czytanie treści zawartych w innych zakątkach interfejsu niż Wiadomości lub zamieszczanie własnych przepisów na kiszonki. W konsekwencji konstrukcja świata oraz doświadczenie czasowości lektury są ze sobą integralnie połączone. Owo połączenie staje się więc ważnym sposobem zaangażowania odbiorców w fabułę.

Innych możliwości w tym zakresie dostarcza sama konstrukcja aplikacji. Jak dowiadujemy się z instrukcji, została stworzona przez władze Destiny jako medium społecznościowe w celu rozpowszechniania propagandowych treści i zwiększenia poczucia wspólnoty. Każdy czytelnik podczas rejestracji loguje się do aplikacji i automatycznie staje się obywatelem tego fikcyjnego kraju, zobowiązanym do przestrzegania praw i zwyczajów w nim panujących. Odbiorcy mają zatem obowiązek codziennej lektury The Daily Scrutinizer i regularnego korzystania z Indeksu: muszą zamieszczać przepisy na kiszonki własnego autorstwa oraz udostępniać i pobierać na swoje urządzenie

Pojęcie "serialności” rozpowszechniły przede wszystkim badania Jasona Mittella, np. Operational seriality and the operation of seriality, w: The Edinburgh companion to contemporary narrative theories, Edinburgh University Press, Edinburgh 2018, s. 227-238 i Complex TV: The poetics of contemporary television storytelling, New York University Press, New York 2015. Zob. również Media of serial narrative, ed. by F. Kelleter, Ohio State University Press, Columbus 2017; T.R. Andersen Staggered transmissions: Twitter and the return of serialized literature, "Convergence. The International Journal of Research into New Media Technologies" 2017 Vol. 23, Is. 1, s. 34-48. 
przepisy innych użytkowników aplikacji. Warto podkreślić, że groteskowości tego pomysłu fabularnego odpowiada bardzo humorystyczny charakter istniejących w systemie przepisów. Co niezwykle ważne, czytelnik jest na bieżąco oceniany ze swojego obywatelskiego zachowania za pomocą tzw. CQ (ang. Citizen Quotient, czyli współczynnik obywatela).W przypadku wszelkiego rodzaju uchybień możemy stać się przedmiotem „oficjalnych Procedur Lojalnościowych", np. gdy nasze CQ spadnie poniżej 8500 punktów lub jeśli ściągniemy na nasze konto jakiś przepis więcej niż raz. W rezultacie aplikacja The Pickle Index niejako wymusza na nas jej codzienne używanie. Oficjalne informacje zostają ogłoszone na ekranie naszego telefonu specjalnym powiadomieniem i aplikacja weryfikuje, czy rzeczywiście otworzyliśmy je i przeczytaliśmy zawarte w nich treści. Aplikacja zakłada zatem wysoki stopień interakcji ze środowiskiem cyfrowym w analogiczny sposób jak gry z gatunku RPG. Algorytmizacja procesu czytania zostaje więc wyeksponowana jako zupełnie nowe doświadczenie czytelnika: ambiwalentne, gdyż wyzwala rozmaite reakcje - od stymulowania ciekawości w oczekiwaniu na ciąg dalszy, po poczucie technologicznej przemocy i poddanie kontroli. Trudno oprzeć się wrażeniu, że intencjonalnie twórcy programu wyeksponowali właśnie to opresywne działanie algorytmu: efekt mechanicznej regulacji staje się doświadczeniowym odpowiednikiem przemocowego systemu politycznego panującego w Destinie. Nasuwa jednak skojarzenia ze współczesną rolą AI oraz algorytmów w realnie istniejących państwach posługujących się wysoko zaawansowanymi technologiami do ustawicznego śledzenia swych obywateli. Pośrednio skłania więc również do refleksji na temat ciemnej strony funkcjonowania mediów we współczesnym świecie.

Skoro aplikacja została wydana przez aparat państwowy, relacje Flory Bialy są tak naprawdę nielegalne. Zamiast wymaganych przepisów na kiszone potrawy Flora zamieszcza w Indeksie „krótkie notatki, smutne i nudne dzienniki opisujące każdy smutny i nudny dzień", określając je mianem „przepisów na deprechę"15. Przykładowe powiadomienie o dostępności posta Flory brzmi następująco: „Psst - w Indeksie poproś o «Zgniłą kapustę» nadesłaną przez Florę Bialy"16. Po ściągnięciu przepisu trafia on do sekcji o tej nazwie; po kliknięciu na nią nie przeczytamy instrukcji przygotowania tego z pewnością pysznego dania, ale opowieść Flory z poprzedniego dnia: „Wrzucili Reubena

15 "These little notes, sad boring diaries of each sad boring day" $i$ "recipes for despair" (Przekąski, S. 27).

16 "Psst - in the Index, request «Rotted Cabbage» by Flora Bialy". 
do celi razem z nami" itd. Ściąanie i czytanie nieoficjalnych treści jest równie wbrew prawu, podobnie jak ich zamieszczanie wThe Pickle Index; czytelnicy stają się zatem współodpowiedzialni za szerzenie nielegalnych treści. Ponieważ Flora opisuje codzienność z perspektywy naocznego świadka, dowiadujemy się o sprawach, które albo zostały pominięte w oficjalnych przekazach, albo przeinaczone. Konflikt dwóch odmiennych wersji rzeczywistości ma swój punkt kulminacyjny dziewiątego dnia. Wówczas, na tzw. Polu Straceń, Flora jest prowadzona na śmierć na oczach licznie zgromadzonych obywateli Destiny, kiedy z publiczności padają następujące słowa:

Ja, naczy mój kumpel przez przypadek słyszał o kimś podobnym do tej dziewczyny, naczy chyba przeczytał o niej w jakimś przepisie, czy coś i chyba to o czym tu powiedziano nie do końca, naczy zastawiam się, że może ci ludzie tutaj nie są wcale żadnymi podżegaczami czy coś?"ᄁ

Podsumowując, aplikacja The Pickle Index znacząco rozszerza storyworld powieści, na co składa się dodatkowo wielość materiału multimedialnego i multimodalnego, mechanizm interaktywny w formie serialności i interfejsu samej aplikacji. Mamy zatem do czynienia z „maszyną do czytania” (określenie N. Katherine Hayles), która zakłada niejako potrójną formę obioru na podstawie projektowanego uczestnictwa odbiorcy w środowisku cyfrowym.

\section{Formy odbioru i modalności immersji}

Pierwszą formą odbioru projektowaną przez aplikację The Pickle Index, choć nie różniącą się w żadnym stopniu od formy projektowanej przez inny tekst literacki, jest czytelnik. Codziennie rano otrzymujemy kolejny rozdział historii i odczytujemy go na ekranie urządzenia. Opowieści te są pozbawione hiperlinków, leksji, obrazów, nagrań wideo czy innych niewerbalnych komunikatów. Dzięki temu czytelnik może całkowicie skupić się na lekturze. Również sam interfejs aplikacji, minimalistyczny pod względem liczby komponentów czy kolorów, pomaga czytelnikom skupić się na czytaniu i sprawia, że samo urządzenie, przenośnik treści powieściowej, staje się niejako transparentne.

17 „A voice came from the darkened bleachers: «l, um, my friend accidentally heard about someone who might have read a, um, recipe that sounds, well, sort of a lot like that girl, and, well, I wonder if it's possible that those guys actually aren't really instigators or whatever?»" (Przekqski, s. 131). 
W rezultacie aplikacja umożliwia nieprzerwane i niczym niezaburzone „zanurzenie" w tekst, pokrewne percepcji tekstu drukowanego oraz jego zdygitalizowanej wersji przeznaczonej na czytnik typu Kindle. Ogranicza on opcje dyspersywnego trybu lektury, nie epatuje efektami wizualnymi czy funkcjonalnościami interaktywnymi. Czytanie w warunkach cyfrowych różni się bowiem od czytania druku różnorodnością aktywności fizyczno-mentalnych i specyfiką efektów kognitywnych ${ }^{18}$. Tymczasem czytelnik The Pickle Index buduje reprezentację mentalną świata przedstawionego na podstawie przede wszystkim materiału werbalnego, wykorzystując własną wyobraźnię. Możemy zatem czytelniczą formę odbioru powieści w tej aplikacji połączyć ze zjawiskiem tzw. immersji fenomenologicznej ${ }^{19}$, wiązanej z odbiorem literatury drukowanej ${ }^{20}$. The Pickle Index daje czytelnikom możliwość harmonijnego połączenia cech komunikacji mobilnej i tradycyjnych form narracji z kultury druku. Trzeba być podłączonym do Internetu, by uzyskać dostęp do różnych części historii, ale nie zagubimy się w nieskończonej sieci hiperlinków lub nie przekierujemy uwagi na symultaniczną interakcję z innymi użytkownikami tej aplikacji. Powieść w aplikacji w tej odsłonie może zatem posłużyć jako lektura przeznaczona do cichego czytania ${ }^{21}$, choć wykorzystuje elementy interaktywnej komunikacji w Internecie, w tym także w mediach społecznościowych.

Po drugie, czytelnik aplikacji The Pickle Index to jednocześnie gracz. Przy rejestracji i pierwszym logowaniu otrzymujemy rolę od odegrania: obywatela oddanego konsumpcji treści propagandowych i kulinarnych. Nasze działania są pod ciągłą obserwacją algorytmu programu i obliczane za pomocą tzw. CQ. Aplikacja zawiera zatem liczne elementy wzmagające grywalizację, przede

18 A. Mangen New narrative pleasures? A cognitive-phenomenological study of the experience of reading digital narrative fictions, Norwegian University of Science, Trondheim 2006.

19 A. Mangen Hypertext fiction reading: haptics and immersion, "Journal of Research in Reading" 2008 No. 31 (4), s. 406.

Immersja ma bogatą literaturę przedmiotu, ograniczamy się do reprezentatywnych pozycji: M.-L. Ryan Narrative as virtual Reality, The Johns Hopkins University Press, Baltimore 2003; J.-N. Thon Immersion revisited: on the value of a contested concept, w: Extending experiences: structure, analysis and design of computer game player experience, ed. by O. Leino et. al. Lapland UP, Rovaniemi 2008, s. 29-42; M.-L. Ryan The Interactive onion. Layers of user participation in digital narrative text, w: R. Page, B. Thomas New Narratives, s. 35-62; P. Kubiński Gry wideo. Zarys poetyki, Universitas, Kraków 2016; M. Kłosiński Hermeneutyka gier wideo. Interpretacja, immersja, utopia, Wydawnictwo IBL PAN, Warszawa 2018.

21 Tak projektowały lekturę psychologiczne badania nad czytaniem oraz badania kognitywne nad obiorem czytelniczym. 
wszystkim związane z grami z gatunku RPG. Ponieważ istnieją one w połączeniu z materiałem werbalnym (powieściowym), moglibyśmy określić The Pickle Index jako „hybrydę ludoliteracką"22. Istotny komponent ludyczny stanowi tu interaktywność, pojmowana nie tylko jako typowy „dialog między umysłem i maszyną" lub „użytkownikiem i tekstem”23, ale również jako współpraca między graczami w świecie opowieści.

Gracze cieszą się pewnym stopniem tzw. interaktywności ontologicznej w trzech ważnych wymiarach. Nie tylko kolekcjonują punkty za „dobre zachowanie", stają się również współtwórcami świata za każdym razem, kiedy wprowadzają swoją treść do zastanej treści aplikacji. Ten gest nosi miano "partycypacji addytywnej”24. Ponadto możemy dokonać „gestu sprzeciwu” względem dyktatorskiego systemu przez regularne ściąganie i czytanie zakazanych relacji Flory Bialy. Gest ten zyskuje dodatkowo charakter metaleptyczny pod koniec powieści, kiedy gracze jako obywatele gromadzą się na Polu Straceń, by zobaczyć egzekucję Flory i jej przyjaciół, i jako widzowie tego wydarzenia mają pośredni udział w obaleniu reżimu. Warto jeszcze dodać, że immersja w rolę gracza w aplikacji (tzw. imersja technologiczna ${ }^{25}$ ) regulowana jest przez wymuszone i ograniczone w czasie użytkowanie aplikacji, co może u części użytkowników powodować zwiększenie zaangażowania w proces gry, gdyż przypomina podejmowanie tzw. wyzwań do wykonania określonej czynności w określonym czasie ${ }^{26}$.

A. Ensslin Literary Gaming, The MIT Press, Cambridge MA-London 2014, s. 40.

M.-L. Ryan The interactive onion, s. 35, por. tejże Avatars of story, University of Minnesota Press, Minneapolis-London 2006, s. 99-107; zob. także N. Montfort Curvship. An interactive fiction system for narrative variation, w: R. Page, B. Thomas New Narratives, s. 104-107; A. Bell Possible Worlds..., s. 1-2.

4 Pojęcie zaproponowane przez Davida M. Meurera odnosi się przede wszystkim do zjawiska, które autor określa "narracją sieciową" ( "network narratives”). "Narracje sieciowe są - w różnym stopniu w zależności od konkretnej kombinacji - dystrybuowane, emergentne, multimodalne, uczestniczące. Często fabuła, postaci, treść i struktura danej narracji sieciowej są kszałtowane przez niepowtarzalne konfiguracje cech dystrybucji, emergencji, multimodalności i uczestnictwa" (D.M. Meurer Conditions of presence: topological complementarities in The Silent History, "Small Screen Fictions” special issue of "Paradoxa” 2017 Vol. 29, s. 246-247).

25 A. Mangen Hypertext, s. 406. Por. J.-N. Thon Immersion revisited i G. Calleja In-game. From immersion to incorporation, The MIT Press, Cambridge MA, 2011.

Zob. A. McMahan Immersion, engagement, and presence. A method for analyzing 3-D video games, w: The Video game theory: reader, ed. by M.J.P. Wolf, B. Perron, Routledge, New York 2003, s. 68-69. 
Trzecia i ostatnia forma odbioru łączy dwie poprzednie i podkreśla haptyczny wymiar aplikacji27. Jako jej uży tkowni cy otrzymujemy dwa wizualno-dźwiękowe powiadomienia na ekran telefonu z kolejnymi rozdziałami narracji. Jednocześnie jesteśmy prawnie zobowiązani do uczestniczenia w świecie powieści jako obywatele Destiny, czytając codziennie treści propagandowe, przesyłając przepisy lub dzieląc się nimi, przeglądając dodatkowe treści (np. Q\&A), analizując mapy kraju itp. Wszystkie powyższe czynności wymagają od nas wykonania konkretnego repertuaru gestów i czynności (tzw. gestemów ${ }^{28}$ ): skrolowanie, klikanie, naciskanie, przytrzymywanie, powiększanie, pomniejszanie, suwanie, pisanie. Gesty te stają się nie tylko semiotycznie nośne jako pojedyncze jednostki znaczeniowe, ale również wywierają wpływ na jakość eksploracji świata przedstawionego i wysoki wynik CQ. Jeśli użytkownicy chcą grać zgodnie z instrukcjami, wchodzą aktywnie w interakcje z urządzeniem tak często, jak to możliwe. W rezultacie haptyczny wymiar aplikacji The Pickle Index staje się fundamentalny dla ogólnego doświadczenia powieści na urządzeniu mobilnym. W połączeniu z aktywizowanym w procesie lektury interaktywnej wzrokiem ${ }^{29}$, dotyk staje się bardzo ważnym komponentem sensorycznym całego doświadczenia wywiera wpływ na całościowe znaczenie powieści ${ }^{30}$.

\section{Aplikacja do kiszenia fabuł}

Ciekawa jest także rola, jaką odgrywa sama aplikacja dla konstruowania fikcyjności w tym niezwykłym przedsięwzięciu artystycznym. Rozpoczynając jej obsługę, wiemy, że została ona stworzona i udostępniona przez władze państwa. Stanowi część większej maszyny propagandowej, z której użytkownicy czerpią informacje na temat wydarzeń z kraju i z której mogą się ze sobą komunikować ( $w$ bardzo ograniczonym zakresie). Aplikacja ma zatem

27 A. Ensslin From (W)reader to breather. Cybertextual de-intentionalization and Kate Pullinger's Breathing Wall, w: New narratives, s. 138-152; C.A. Milligan The Page is a touchscreen: haptic narratives and "novel" media, "Paradoxa” 2017 Vol. 29, s. 287-312.

S. Bouchardon Figures, s. 162-163.

J.-N. Thon Immersion, w: The Johns Hopkins guide to digital media, ed. by M.-L. Ryan, L. Emerson, B.J. Robertson, The Johns Hopkins University Press, Baltimore 2014, s. 269-272; J. Murray Hamlet on the holodeck. The future of narrative in cyberspace, Free Press, New York 1997.

A. Mangen, A. van der Weel The evolution of reading in the age of digitization: An integrative framework for reading research, "Literacy” 2016 Vol. 50, Is. 3. s. 5; G. Kress Literacy in the new media age, Routledge, London-New York 2003. 
bardzo jasno określony cel - wzmacniać władzę reżimu przez dystrybuowanie oficjalnych wiadomości i skupianie aktywności obywateli na produkcji i konsumpcji jedzenia (z tego względu kolorystyka interfejsu aplikacji jest nie tylko nieprzypadkowa, ale wręcz symboliczna). Kolorystyka interfejsu została zdominowana przez ciepłą paletę barw, a najważniejsze kolory to zieleń, brąz i żółć, przywołujące na myśl kiszonki gotowe do spożycia. Jednocześnie aplikacja działa jako narzędzie masowej inwigilacji i zbierania danych na temat obywateli.

Z drugiej jednak strony, jak każdy twór zaprojektowany i wykonany na zlecenie władz państwa, aplikacja nie jest doskonała, pozwala bowiem na formę sprzeciwu. Flora Bialy demonstruje, jak z narzędzia do inwigilacji obywateli można uczynić broń oporu. Przemyca nielegalne treści, zamieszczając je w aplikacji jako przepisy, i informuje nas o wydarzeniach w kraju ze swojej perspektywy. Z kolei każdy kto czyta jej nielegalne posty, automatycznie również popełnia przestępstwo. Zwieńczeniem tego wywrotowego zachowania jest oczywiście scena kulminacyjna, w której czytelnicy „biorą udział” w egzekucji Flory i jej przyjaciół, a następnie w obaleniu władz. Aplikacja została więc zaprojektowana jako część światoopowieści i jej uruchomienie z poziomu ekranu oznacza automatyczne przejście ontologicznej i diegetycznej granicy między rzeczywistością odbiorcy a rzeczywistością narracji. Elementy interfejsu pełnią funkcję komponentów owego świata oraz umożliwiają poznawanie losów bohaterów fikcyjnych (odbieranie tajnych postów Flory), jak i wysyłanie przepisów do realnie istniejących poza programem osób (np. znajomych czytelnika). Program więc wzmaga i demaskuje fikcyjność jednocześnie.

Sam interfejs jest łatwy w użyciu i graficznie uproszczony. Oczywiście jest on multimodalny - użyto przy jego konstrukcji dwóch kodów semiotycznych: werbalnego i wizualnego. Przy otwarciu aplikacji użytkownikowi ukazuje się koło podzielone na trzy równe segmenty, odnoszące się do trzech najważniejszych elementów aplikacji: „Wiadomości”,,Przepisy” i „Indeks”; w jego środku obraca się czerwony sześcian. Ów widok stanowi również ekran początkowy. W jego tle widzimy rozmazaną mapę Destiny i sąsiednich krajów. Jeśli kliknie się na mapę, koło i sześcian znikają w dole, a naszym oczom ukazuje bardziej szczegółowa, choć nadal niedokładna, mapa miejsca akcji; Destina, jako stolica i największe miasto, umieszczona została na środku mapy i ekranu. Między nią a innymi miastami poruszają się żółte przerywane linie symbolizujące transfer przepisów między "skrolerami” (nazwa smartfonu w powieści). Jeśli chcemy powrócić do ekranu głównego, musimy nacisnąć „HOME” 
na czarnym pasku u dołu ekranu. Ponad mapą i kołem widzimy bladobiałą belkę z napisem „THE PICKLE INDEX” (na środku), symbol znaku zapytania wpisany w niebieskie koło (w prawym górnym rogu) - sekcja Q\&A, oraz trzy krótkie poziome linie, czyli menu aplikacji (jedyny paratekstowy element). Nietrudna nawigacja odgrywa istotną rolę w użytkowaniu aplikacji, gdyż ma ona w zamyśle twórców być używana regularnie, jak najczęściej nawet, w ciągu owych dziesięciu dni zabawo-lektury.

\section{The Pickle Index, czyli metamedialna sałatka}

Umiejscowimy teraz aplikację Eli Horowitza i Russella Quinna w szerszym kulturowym kontekście. Nowe media stanowią poważne wyzwanie dla badań nad czytelnictwem i odbiorem literackim. Jako multimedialna seria, The Pickle Index sprawia, że czytelnicy stają się bardziej świadomi różnic pomiędzy lekturą tekstu cyfrowego (np. na Kindle'a), interpretacją materiałów wizualnych w drukowanej literaturze ${ }^{31}$ czy w literaturze eksperymentalnej ery cyfrowej ${ }^{32}$, między grami z gatunku RPG, grami literackimi oraz zjawiskami interaktywnymi w mediach społecznościowych. Ten intermedialny i transmedialny kontekst wywiera obecnie silny wpływ także na tradycyjne formy literackie i ich odbiór ${ }^{33}$, zmieniając przyzwyczajenia i oczekiwania czytelnicze. Odbiorca The Pickle Index może wejść w świat wirtualny na małym ekranie lub stworzyć świat w efekcie własnej mentalnej reprezentacji podczas odczytywania werbalno-wizualnego tekstu dwóch drukowanych wersji. Za nadrzędny artystyczny cel projektu można zatem uznać eksperyment ze sposobem projektowania (w znaczeniu design) narracji. Czytelnik ma niepowtarzalną okazję do wybrania sposobu lektury i porównania go $\mathrm{z}$ innymi sposobami w trakcie zmian trzech różnych formatów powieści. Innym celem (równie ważnym) jest sprawowanie kontroli nad doświadczeniem lektury zgodnie z rodzajem medium, którego wykorzystujemy jako punkt „wejścia” w opowieść.

31 J. Bateman Text and image: a critical introduction to the visual/verbal divide, Routledge, London 2014.

The Routledge companion to experimental literature, ed. by J. Bray, A. Gibbons, B. McHale, Routledge, London-New York 2012. nym zostają opisane w treści powieści, zarówno na poziomie fabuły, jak i opowieści. 


\section{Lektura indywidualna a interakcja społeczna}

Internetowe technologie mobilne wzmocniły rolę czynnika kolektywnego i wagę czynności wspólnego czytania i pisania ${ }^{34}$. Do pewnego stopnia także czytelnicy aplikacji The Pickle Index nie są całkowicie odizolowani od świata i od tłumu internetowego. „Networking” to domyślna czynność czytelnika The Pickle Index jako fikcyjnego obywatela państwa totalitarnego. Możliwość rozsyłania treści (przepisów na ogórki) stanowi podstawowy mechanizm odniesienia do rzeczywistych interakcji w mediach społecznościowych, choć trudno nie uznać humorystycznego, czy wręcz parodystycznego charakteru tego rozwiązania. Ten sposób budowania społeczności można odebrać jako parodię współczesnej potrzeby ciągłej interakcji z ludźmi w mediach społecznościowych. Jako członkowie tej fikcyjnej społeczności, czytelnicy mogą przenieść część swoich aktywności poza fikcyjny świat i rozsyłać przepisy zawarte $\mathrm{w}$ aplikacji prawdziwym ludziom. To z jednej strony typowe zachowanie uczestników mediów społecznościowych, ale zarazem strategia promocyjna samej serii multimedialnej. W rezultacie, doświadczenie transmedialnej narracji przestaje być transparentne (tożsame) i nie może być uznane za aktywność jednoosobową. Konkretni czytelnicy i postaci fikcyjne zostają włączeni w jedną społeczność. Jednakże owa społeczność wirtualna jest inna niż kolektyw graczy gier wideo i awatarów (lub innych aktywnych uczestników) w świecie opowieści.

\section{Immersywne czytanie a immersywne współ-granie}

Współpraca lub zaangażowanie przypominające rywalizację w grach wideo ${ }^{35}$ wielu osób jednocześnie wzmacnia pozycję użytkownika powieści w aplikacji. Doświadczenie lektury utworu tego gatunku zawiera zatem nowe cechy uczestnictwa w utworze narracyjnym - zawiera elementy wspólnych działań i interakcji w czasie rzeczywistym. Tę jakość doświadczeniową utrwaliły przede wszystkim nowe platformy komunikacyjne, przede wszystkim te, które dają możliwość tzw. live streamingu w wielu formatach i ramach czasowych

34 Zob. D. Ciccoricco Reading network fiction, University of Alabama Press, Tuscaloosa 2007; R. Page Stories and social media: identities and interaction, Routledge, London, 2012; tejże Narratives online. shared stories in social media, Cambridge University Press, Cambridge 2018.

35 O współdziałaniu [shared involvement] piszą G. Calleja In-game, s. 93-112; M. Kłosiński Hermeneutyka..., s. 95-134. 
(np. Facebook Watch, SnapChat, Periscope ${ }^{36}$ ). Promują one jednoczesność i wielość punktów widzenia oraz wspólne tworzenie treści. W tym kontekście immersja nabiera nowych cech: wspólna obecność wielu uczestników danego wydarzenia, ich natychmiastowe reakcje zwrotne, wspólne emocjonalne odpowiedzi i wielość równorzędnych perspektyw. Współuczestnictwo we wspólnym wydarzeniu wydaje się najbardziej pożądaną jakością dla odbiorców nowych mediów, w tym również czytelników! Mimo że w aplikacji The Pickle Index bezpośrednie interakcje pomiędzy użytkownikami są głównie stematyzowane na poziomie opowieści, networking wydaje się istotnym elementem zaangażowania czytelnika w ten utwór. Partycypacja w konspiracji przeciwko reżimowi poprzez lekturę nielegalnych postów stawia czytelnika na pozycji uczestnika w wydarzeniach typu „flash mob”. Są one wewnętrznie skorelowane z wpływem mediów społecznościowych i aktywizują samoorganizację społeczności. Nie może być to zatem przypadek, że powieść nawiązuje do tego typu zachowań. Nie może być przypadkiem również to, że media społecznościowe dają możliwości samoorganizacji dla społecznych i politycznych ruchów, w tym tych, których celem są zadania wywrotowe. Wystarczy przypomnieć sobie Arabską Wiosnę z 2010 roku, podczas której media społecznościowe stanowiły potężny oręż dla uczestników protestów. Wystarczy mieć w pamięci, jak ważne dla każdej dyktatury jest kontrolowanie mediów - zwłaszcza cenzurowanie lub w ogóle odcinanie dostępu do Internetu i mediów społecznościowych, za pośrednictwem których komunikują się grupy nieformalne. Na naszych oczach ten prodemokratyczny potencjał nowych mediów jest ograniczany np. przez Aleksandra Eukaszenkę w czasie tłumienia protestów po sfałszowanych wyborach prezydenckich na Białorusi w sierpniu 2020 roku.

\section{Czytanie a udostępnianie i dzielenie się treściami}

Apologia kontaktu bezpośredniego i szybkiego dzielenia się treściami stały się atrybutami komunikacji nowych mediów społecznościowych, np. Facebooka. Dzielenie się treściami własnymi i udostępnianie cudzych towarzyszy nawiązywaniu społecznych kontaktów i jest domyślną aktywnością implikowanego użytkownika takiej platformy. Facebook umożliwia te czynności na

36 O. Haimson, J. Tang What makes live events engaging on Facebook Live, Periscope, and Snapchat www.microsoft.com/en-us/research/wp-content/uploads/2017/05/CHILiveEvents.pdf (15.08. 2020). 
podstawowym poziomie interfejsu poprzez specjalnie zaprojektowane funkcjonalności systemu (znowelizowany interfejs Facebooka, „Oś czasu" ${ }^{\text {37 }}$ od 2011 roku, zaowocował także nowym gatunkiem komunikacyjnym zwanym „małymi opowieściami”38). Poszczególne funkcje tego medium (możliwość polubienia treści, dzielenia się, emotikony, gify) uznawane są za współczesne kanały komunikacyjne oraz nowe formy ekspresji w kulturze ${ }^{39}$.Z tego powodu, stanowi ono ważne narzędzie do tworzenia i wzmacniania tożsamości kolektywnych ${ }^{40}$.Te zjawiska medialne znajdują swoje odzwierciedlenie także w poetyce The Pickle Index. Poprzez swoje (tylko pozornie) samotne pisarstwo, Flora przypadkowo tworzy zjednoczoną społeczność gotową do walki o swoje prawa. Dzielenie się rzekomymi przepisami na kiszonki w aplikacji The Pickle Index to oczywista parodia gatunku "małych opowieści” i zachowań użytkowników nowych mediów. Jednak wywrotowa aktywność Flory przybiera formę zamieszczania postów i ich udostępniania przez inne osoby. Nielegalna lektura postów Flory konstytuuje społeczność jej zwolenników (ang.followers) i potencjalnie aktywnych popleczników. W tym właśnie sensie czytanie kolejnych rozdziałów opowieści Flory okazuje się przewrotnie aktem sprzeciwu wobec autorytarnego państwa, który podejmuje także czytelnik aplikacji.

\section{Zakończenie}

Nawyki, praktyki i oczekiwania aktywnej i nieoficjalnej społeczności internetowej stają się coraz bardziej istotnym kontekstem badań nad wszelkimi formami komunikacji literackiej, czytania i pisania ${ }^{41}$. Bez tego kontekstu

37 J. van Dijk The culture of connectivity: a critical history of social media, Oxford University Press, Oxford 2013, s. 54-57.

38 A. Georgakopoulou Small stories, interaction and identities, John Benjamins, Baltimore 2007, S. 42.

S. Iversen Narratives and online decorum: the rhetoric of Mark Zuckerherg's personal storytelling on Facebook, "Style” 2017 Vol. 52, Is. 3, s. 374-391.

R. Page Narratives Online..., s. 83-120.

Na temat wpływu kultury partycypacyjnej także na tradycyjne praktyki piśmienne zob. C. Pearce The interactive book: a guide to the interactive revolution, Macmillan, Indianapolis 1997; J. Jenkins Fans, bloggers, gamers: exploring participatory culture, New York University Press, New York 2006; tegoż Kultura konwergencji. Zderzenie starych i nowych mediów, przeł. M. Bernatowicz, M. Filiciak, AiP, Warszawa 2007; Beyond the screen transformations of literarystructures, interfaces and genres, ed. by J. Schäfer, P. Gendolla, Transcript-Verlag, Bielefeld 2010; N.K. Hayles How we think. Digital media and contemporary technogenesis, The University of Chicago Press, 
powieść w aplikacji byłaby niemożliwa. Dlatego The Pickle Index stanowi doskonały przykład jak wiele zjawisk transmedialnych może na siebie nachodzić i łączyć ze sobą. The Pickle Index należy uznać za bardzo udany projekt artystyczny. Powieść ta w celowy sposób zmienia czytelników w osoby, które znalazły się na obrzeżach galaktyki Gutenberga i jej peryferiach (czyli graczy i użytkowników). Pozwala nam czytać tradycyjną, pozbawioną elementów interaktywnych opowieść (dość błahą w treści, pełną znaczeń metamedialnych) w środowisku cyfrowym w połączeniu z elementami rozgrywki i mediów społecznościowych. Wprowadza element gry z indywidualnym doświadczeniem lekturowym zależnym od różnych formatów technicznych. Daje namiastkę możliwości utrzymywania kontaktów z innymi użytkownikami medium, społecznych interakcji: zarówno na poziomie ich tematyzacji, jak i dzięki funkcjonalności wysyłania własnych treści osobom realnym i fikcyjnym. Umożliwia nam rozpoznanie nietożsamości doświadczenia lektury w medium drukowanym i cyfrowym, nie uprzywilejowując wcale form najbardziej interaktywnych, utożsamianych często z zagrożeniem dla samej idei kultury druku. Jeśli mielibyśmy się pokusić o próbę oceny przyszłości tego (rzadkiego jeszcze) gatunku, to być może zmierza on w tym kierunku, by zaszczepić lub wzmocnić autonomię cichego, skupionego czytania w środowisku cyfrowym, w kontrze do plątaniny linków hipertekstu. W omówionej powieści aplikacji ta sztuka się udała.

Chicago 2012; M. Maryl Życie literackie w sieci, Wydawnictwo IBL PAN, Warszawa 2015; F. Furedi The Power of reading (Kindle version) 2015; K. Gajewski (w druku) Tryumf amatora. Tekstualne praktyki uczestnictwa w świecie elektronicznych mediów cyfrowych. 


\section{Abstract}

\section{Bartosz Lutostański}

UNIVERSITY OF WARSAW

\section{Magdalena Rembowska-Płuciennik}

THE INSTITUTE OF LITERARY RESEARCH OF THE POLISH ACADEMY OF SCIENCES (WARSAW)

The App Novel: Between Slow Reading and High-Speed Internet

Rembowska-Płuciennik explores a new form of literature to be found online: the use of mobile apps as a carrier for the novel, such as the pioneering artistic endeavour that is the multimedia series The Pickle Index. The project involves print book, a mobile app and a version for ebook readers. The construction of the narrative in different parts of this artistic project is examined from a comparative multimedia perspective to demonstrate that the key theme of The Pickle Index is the intentional collision between the readers' different needs, reading practices and communication habits in the era of multimedia reading.

\section{Keywords}

The Pickle Index, app novel, immersion, social media, transmediality, multimodality, reception studies 